\title{
Using Utility Information to Calibrate Customer Demand Management Behavior Models
}

\author{
Murat Fahriog̃lu, Student Member, IEEE and Fernando L. Alvarado, Fellow, IEEE
}

\begin{abstract}
In times of stress customers can help a utility by means of voluntary demand management programs if they are offered the right incentives. The incentives offered can be optimized if the utility can estimate the outage or substitution costs of its customers. This paper illustrates how existing utility data can be used to predict customer demand management behavior. More specifically, it shows how estimated customer cost functions can be calibrated to help in designing efficient demand management contracts.
\end{abstract}

Index Terms-Contract design, customer cost, data calibration, demand management, load curtailment, system security.

\section{INTRODUCTION}

$\mathbf{M}$ ANY transmission and most distribution problems can be addressed by means of effective demand management programs [4]. Mechanism design theory [6] has been utilized to optimize the contracts to maximize utility benefit and to make sure customers see a benefit by signing up (this formulation was developed in [5]). This paper shows how a cost function satisfying the conditions for mechanism design can be developed and calibrated. Utilities around the country are using nonlinear pricing to sell their power (anytime a utility offers different rates based upon customer size, it is using nonlinear pricing). The demand management contracts proposed in [5] use nonlinear pricing to buy it back in case of emergencies. Estimated customer cost functions plays a crucial role in designing demand management contracts. In [1], [2] authors suggest different ways of estimating the outage costs of customers mainly by way of interacting with the customers. In [9], the main goal is to design priority electric service options for the customer and part of the process is to estimate the customer outage costs by way of surveys.

This paper proposes the use of existing utility data to estimate these customer cost functions. Customer outage costs (or substitution costs) can be modeled using a variety of general functions. Several functions with general coefficients are proposed and their coefficients are calibrated using real data obtained from existing utility demand management programs. The data available provides information on how much each customer gets paid by providing a certain amount of relief. The main goal of this calibration process is to find a practical cost function that accurately models the demand management behavior

Manuscript received January 26, 2000. This work was supported by the Energy Center of Wisconsin.

The authors are with the Department of Electrical and Computer Engineering, The University of Wisconsin-Madison.

Publisher Item Identifier S 0885-8950(01)03800-7.

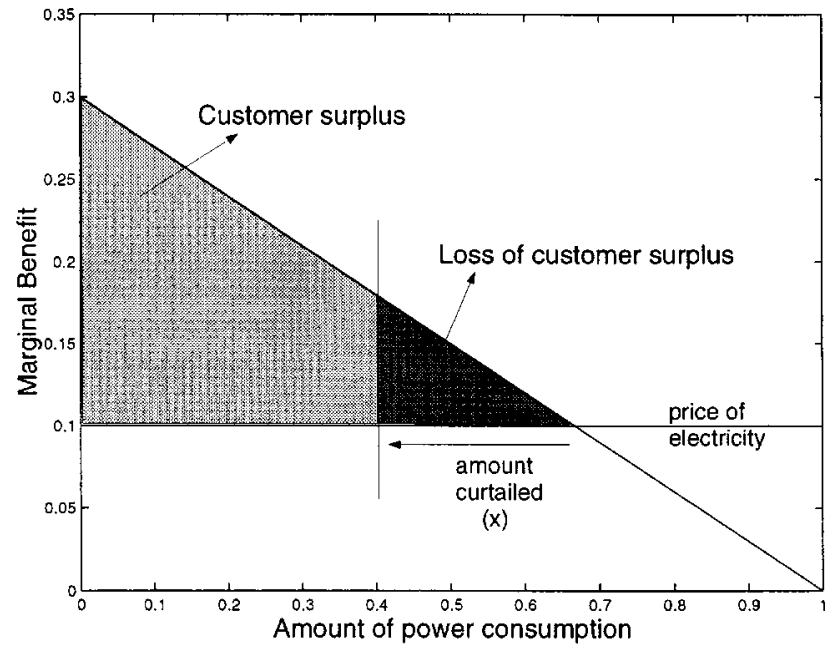

Fig. 1. Marginal benefit for a customer. Areas in this figure denote total surplus.

of customers, and to use it to design contracts. Existing data and the calibrated cost functions are then used to validate the formulation by means of some examples.

\section{Customer Cost Function Characteristics}

The first assumption made in designing a cost function is that it costs the customer progressively more to shed more load. It is safe to assume that the marginal benefit of the customer decreases with increased electricity consumption. Fig. 1 shows a possible predicted marginal benefit of a customer from electricity consumption. The dark shaded area in Fig. 1 shows the loss of surplus as a customer curtails its power. This loss of surplus due to shedding load is the outage cost for the customer. If the marginal benefit is assumed to be linear, as the customer sheds power its surplus loss cost function is quadratic. This quadratic or any other cost function needs to satisfy the sorting (or "single crossing") condition [6]. This condition is needed to be able to rank the customers in order of increasing or decreasing marginal cost. The cost function is a function of the amount of power curtailed $x$ and the customer type $\theta$. Different types of customers are parameterized by $\theta$. This will become more clear later on in this section. The outage cost function of a customer is given by $c(\theta, x)$. If the customers are sorted from least willing (to shed load) to most willing, the sorting condition dictates that:

$$
\frac{\partial}{\partial \theta}\left(\frac{\partial c}{\partial x}\right)<0
$$


Likewise, if the customers are sorted from most willing to least willing, the sorting condition becomes:

$$
\frac{\partial}{\partial \theta}\left(\frac{\partial c}{\partial x}\right)>0
$$

Whether one sorts customers according to increasing or decreasing willingness is a matter of preference and is irrelevant (we assume increasing willingness). The important issue is that the outage cost function be nondecreasing in $x$ and $\theta$. The outage cost function needs to be nondecreasing in $x$ since it is assumed that shedding each extra $\mathrm{kW}$ brings additional cost to the customer. Since $\theta$ is used only to sort the customers, it can be normalized to be in the interval $0 \leq \theta \leq 1$. The cost function also needs to be convex, i.e., the rate of change in the marginal cost is assumed to be increasing as the customer sheds more load. This is an economic assumption which is justified for most customers. ${ }^{1}$ Finally $c(\theta, 0)=0$ since shedding zero power should cost zero. All these conditions on the outage cost function can be summarized as:

$$
\begin{aligned}
\frac{\partial}{\partial \theta}\left(\frac{\partial c}{\partial x}\right) & <0 \\
\frac{\partial c}{\partial x} & \geq 0 \\
\frac{\partial^{2} c}{\partial x^{2}} & >0 \\
c(\theta, 0) & =0
\end{aligned}
$$

for all $x \geq 0$ and $0 \leq \theta \leq 1$.

In order to explain the procedure of forming an outage cost function that fits the conditions stated above, the shape of the customer outage cost function is assumed to be a quadratic (other possible forms will also be addressed later). A general quadratic form using Taylor Series for each type of customer (different types of customers are parameterized by $\theta$ ) is defined as:

$$
c(\theta, x)=c_{0}+a \theta+b x+\frac{1}{2} d x^{2}+e x \theta+\frac{1}{2} f \theta^{2} .
$$

Using constraint (6) it can be shown that $c_{0}=0$.

Since

$$
\frac{\partial c}{\partial x}=b+d x+e \theta
$$

it is observed using (5) that $d>0$. Also (3) gives $e<0$. Finally using (4)

$$
b+d x+e \theta \geq 0,
$$

$\forall x \geq 0$ and $0 \leq \theta \leq 1$ it can be shown $b \geq-e$. Thus, it is sufficient to express the quadratic outage cost function in the following form:

$$
c(\theta, x)=K_{1} x^{2}+K_{2} x-K_{2} x \theta
$$

where $K_{1}$ and $K_{2}\left(K_{1}=1 / 2 d>0, K_{2}=b>0\right.$ and $-K_{2}=$ e) are the coefficients of the general cost function that needs calibrating. The $-K_{2} x \theta$ term makes sure that different values of $\theta$ lead to different values of $\partial c / \partial x$ (marginal cost for the

\footnotetext{
${ }^{1}$ The rate of increase of cost as a customer sheds load will also be dependent on the presence of a curtailment notice. Curtailments made without notice usually imply higher costs for the customer.
}

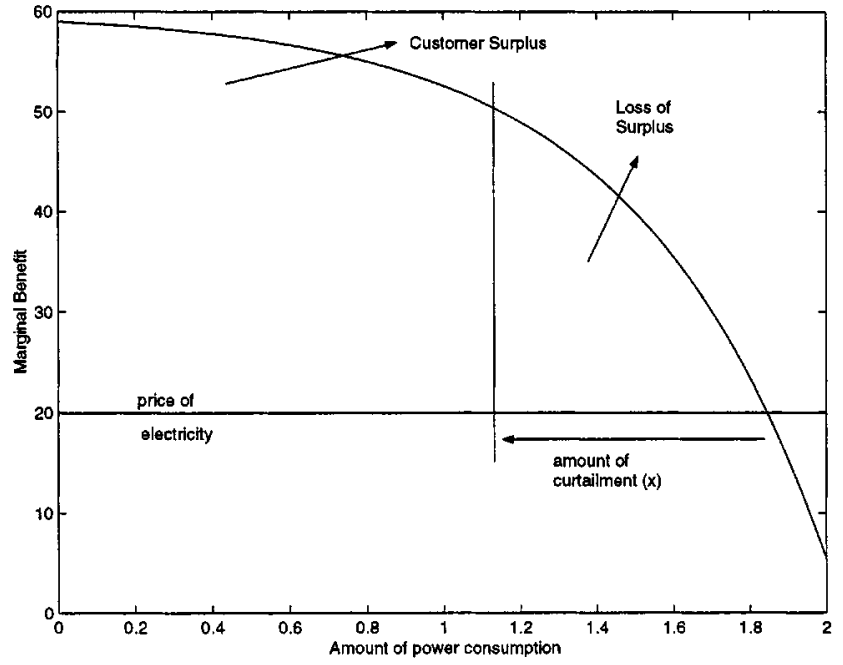

Fig. 2. Exponentially decreasing marginal benefit for a customer.

customer). As $\theta$ increases the marginal cost decreases. That is, $\theta$ "sorts" the customers from "least willing" to "most willing" to shed load. This form of the cost function suggests that the customer with the lowest $\theta$ has the highest marginal cost and hence the lowest marginal benefit. This provides a good way of modeling the willingness of each customer to shed load by way of $\theta$.

Following similar design process, one can also assume a cubic outage cost function:

$$
c(\theta, x)=C_{1} x^{3}+C_{2} x^{2}+C_{3} x-C_{3} x \theta
$$

where the number of coefficients to be calibrated is now 3 $\left(C_{1}, C_{2}\right.$ and $C_{3}$ all nonnegative). However, with limited utility data bringing extra coefficients into the cost function to make it more detailed will not provide more accuracy in estimating the customer outage cost function. A quadratic is sufficient to use existing data ${ }^{2}$ for the purposes of demand management contracts. Reference [9] points out that "The welfare loss, or outage cost, scales approximately as the square of the load changes." Thus, this paper models the customer outage cost function as a quadratic. ${ }^{3}$

In order to analyze the robustness of the formulation to changes in the form of the cost function, it was decided to also test an exponential function to model the outage costs of customers. A marginal benefit of the customers that decays exponentially is shown in Fig. 2. The marginal benefit function shown is in the form of:

$$
m b=-a e^{b x}+k
$$

where $a, b$ and $d$ are general coefficients. The cost of curtailing power (shown as loss of surplus in Fig. 2) is then the integral of equation (12) in the shown region. This yields an exponential function for the surplus loss in the form of:

$$
c(x)=-\frac{a}{b} e^{b x}+k x
$$

${ }^{2}$ Calibration of the customer outage cost function will be explained in the next section.

${ }^{3}$ After a certain point the customer will not be able to shed any more load and the marginal cost of shedding load will be zero. We focus on the quadratic part of the cost curve only. 
The following function is sufficient to satisfy the cost function constraints (3) thru (5) $\left(k_{1}\right.$ is small enough that constraint (6) is also satisfied):

$$
c(\theta, x)=k_{1} e^{k_{2} x / \theta}
$$

where $k_{1}$ and $k_{2}$ are the coefficients to be calibrated $\left(k_{1}, k_{2}>\right.$ $0)$. This function also was designed to sort the customers from least willing to most willing to shed load since the marginal cost of shedding load decreases as $\theta$ increases.

\section{Calibration of Cost Function CoefFicients using AVAliable Data}

The next step is to use available utility data in order to estimate the coefficients of the assumed outage cost functions. The utilities providing the data have different rates for different types of customers. A customer that provides $x \mathrm{~kW}$ of relief for up to a designated number of hours at a rate of $r$ dollars per $\mathrm{kWh}$ receives $r x$ dollars per hour of monetary credit. Hence the benefit function for a customer under a demand management contract is:

$$
b_{c}(\theta, x)=r x-c(\theta, x) \text {. }
$$

The assumption is that a customer who wishes to maximize its benefit will choose to curtail $x \mathrm{~kW}$ of load, where $x$ satisfies the first order condition of its benefit function (this can be used if the customer benefit function is strictly concave in $x$ ):

$$
\frac{\partial b_{c}}{\partial x}=r-\frac{\partial c}{\partial x}=0 .
$$

The data provided by the utilities was obtained from customers who participated in interruptible rates program. These customers designate a certain amount of their load for interruption and in return the utility pays them a fixed rate. Specifically the data shows the amount of power each participating customer is willing to shed and the amount the utility is willing to pay them per $\mathrm{kWh} .{ }^{4}$ The main assumption is that each customer acts in their own best interest.

In order to illustrate how the calibration is performed, the quadratic form of the cost function is assumed. Since the customers want to maximize their own benefit the first order condition (16) yields:

$$
r-2 K_{1} x-K_{2}+K_{2} \theta=0 .
$$

Assume $n$ customers in the provided data. Using the first order condition (17) for each customer gives $n$ equations and $n+$ 2 unknowns ( $K_{1}, K_{2}$ and all the $\theta$ 's). Since $\theta$ is normalized to the interval $[0,1]$, its value for the most and least willing (able) customer to shed load needs be specified as zero and one respectively. This yields $n$ equations and $n$ unknowns. The rate $r$ and selection of curtailment $x$ for each customer is known from the utility data. This method provides values for $K_{1}, K_{2}$ and estimates for customer types $(\theta \mathrm{s})$.

In order to illustrate the calibration method described above, a sample of 10 customers are taken from the data provided by a utility. Customers willing to shed less than $500 \mathrm{~kW}$ get paid $\$ 3.25$ per designated $\mathrm{kW}$ for a nominal hour of interruption and

\footnotetext{
${ }^{4}$ Utilities also specify time limits for the duration of the interruption and have a limit on the number of interruptions per year.
}

TABLE I

UTILITY DATA: AMOUNT OF CUSTOMER LOAD DESIGNATED FOR CURTAILMENT

\begin{tabular}{cc}
\hline Customer & Amount of load (kW) \\
\hline 1 & 59 \\
2 & 100 \\
3 & 130 \\
4 & 134 \\
5 & 151 \\
6 & 184 \\
7 & 200 \\
8 & 349 \\
9 & 364 \\
10 & 770 \\
\hline
\end{tabular}

TABLE II

CALIBRATION RESUltS FOR THE 10 CUSTOMER EXAMPLE

$$
\begin{aligned}
& K_{1}=0.0019 \\
& K_{2}=3.0201 \\
& \theta_{1}=0 \\
& \theta_{2}=0.0529 \\
& \theta_{3}=0.0916 \\
& \theta_{4}=0.0968 \\
& \theta_{5}=0.1187 \\
& \theta_{6}=0.1613 \\
& \theta_{7}=0.1819 \\
& \theta_{8}=0.3741 \\
& \theta_{9}=0.3935 \\
& \theta_{10}=1
\end{aligned}
$$

the customers that shed load above $500 \mathrm{~kW}$ get $\$ 3.00$ per designated $\mathrm{kW}$. The amount of load each customer agreed to curtail is shown in Table I. The described method is applied to find the coefficients of the cost function and the estimates of customer types $(\theta \mathrm{s})$. The results are shown in Table II. These results give us a cost function that is calibrated for these customers. This function can be used to design demand management contracts.

\section{Using CALIBRATEd COST FunCTIONS FOR CONTRACT DESIGN}

After the cost function is calibrated, mechanism design can be applied to design the demand management contracts. The factors that affect the contract design procedure are summarized in Fig. 3. In reference [5] and in Section II a general formulation was developed where $\theta$ was a continuous variable with a given probability distribution in the interval $[0,1]$. This chapter develops the formulation where $\theta$ can take discrete values, each with a presumed probability $p$. This allows the design of customer-specific contracts.

Assume $n$ number of customers, each with an assumed quadratic outage cost function:

$$
c_{i}=K_{1} x_{i}^{2}+K_{2} x_{i}-K_{2} x_{i} \theta_{i},
$$

for $i=1,2, \ldots, n$. The object of the mechanism design formulation is to determine the optimal amount of payment for each customer who agrees to curtail $x \mathrm{~kW}$ in order to maximize utility benefit. Let the monetary payment be $y$ dollars per $\mathrm{kWh}$. The monetary benefit for each customer becomes:

$$
u_{i}=y_{i}-\left(K_{1} x_{i}^{2}+K_{2} x_{i}-K_{2} x_{i} \theta_{i}\right) .
$$




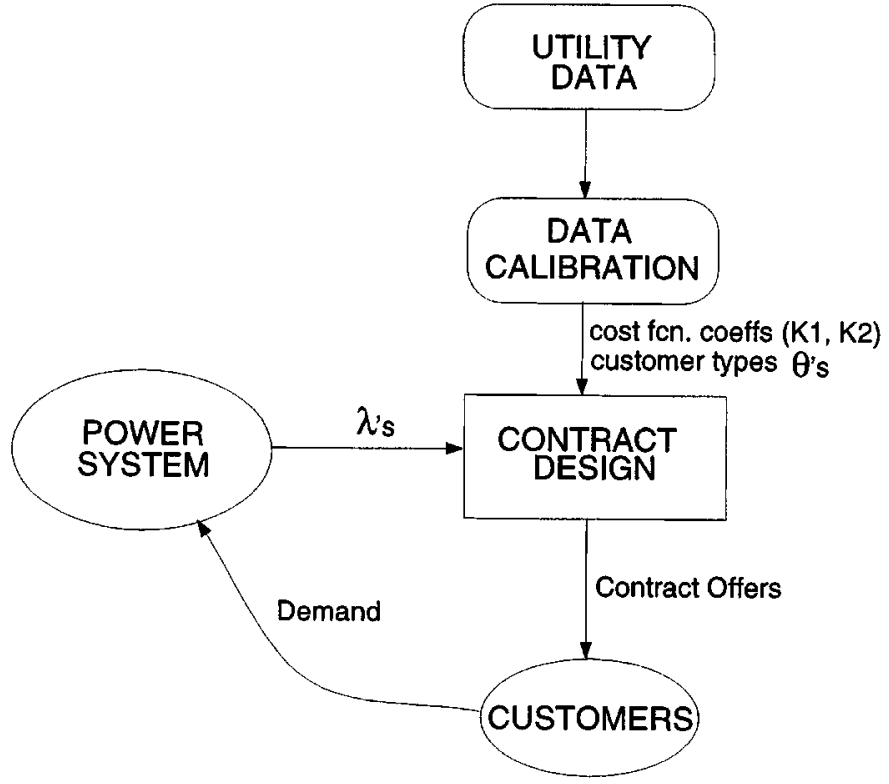

Fig. 3. A summary of the contract design procedure.

The benefit to the utility 5 of not delivering power to a specific customer under conditions of system stress is $\lambda_{i}$ dollars per $\mathrm{kWh}$. Under these conditions the utility benefit function is:

$$
u_{0}=\sum_{i=1}^{n} \lambda_{i} x_{i}-y_{i}
$$

Since the objective is to maximize the expected benefit for the utility:

$$
\max _{x, y} \sum_{i=1}^{n}\left[\lambda_{i} x_{i}-y_{i}\right] p_{i}
$$

subject to,

$$
y_{i}-\left(K_{1} x_{i}^{2}+K_{2} x_{i}-K_{2} x_{i} \theta_{i}\right) \geq 0
$$

for $i=1,2, \ldots, n$, and

$$
\begin{aligned}
& y_{i}-\left(K_{1} x_{i}^{2}+K_{2} x_{i}-K_{2} x_{i} \theta_{i}\right) \\
& \quad \geq y_{i-1}-\left(K_{1} x_{i-1}^{2}+K_{2} x_{i-1}-K_{2} x_{i-1} \theta_{i}\right)
\end{aligned}
$$

for $i=2, \ldots, n$. Constraint (22) is the individual rationality constraint which encourages voluntary customer participation by keeping customer benefit positive. Constraint (23) is the incentive compatibility constraint which makes sure the customers do not try to take the adjacent contracts, by offering them extra money to voluntarily take the contract designed specifically for them.

The cost function is designed to sort the customers in decreasing marginal cost order, i.e., the customer defined by the lowest value of $\theta$ (customer 1) will have the highest cost to shed load. Since the utility wants to pay as little as possible, it should be clear that the individual rationality constraint binds for customer 1 (if the individual rationality constraint does not bind for customer 1, we can shift all the payments by the same

\footnotetext{
${ }^{5}$ When the system is under stress it is not beneficial for the utility to deliver power to certain locations. It may be quite costly, or worse yet, the utility may face forced outages.
}

amount until it does. This does not affect the incentive compatibility constraints since the shifting is done to both sides of the equation),

$$
y_{1}-\left(K_{1} x_{1}^{2}+K_{2} x_{1}-K_{2} x_{1} \theta_{1}\right)=0 .
$$

Since the utility wants to pay the customers as little as possible, the incentive compatibility constraints bind for $i=2, \ldots, n$. If they did not bind, the utility can lower the payments until it does. Using the binding individual rationality and incentive compatibility constraints, the incentive for each customer can be expressed in terms of the curtailed load $(x)$ and the customer type $(\theta)$ :

$$
\begin{aligned}
y_{1}= & K_{1} x_{1}^{2}+K_{2} x_{1}\left(1-\theta_{1}\right) \\
y_{2}= & K_{1} x_{2}^{2}+K_{2} x_{2}\left(1-\theta_{2}\right)+K_{2} x_{1}\left(\theta_{2}-\theta_{1}\right) \\
& \vdots \\
y_{n}= & y_{n-1}+K_{1} x_{n}^{2}+K_{2} x_{n}\left(1-\theta_{n}\right)-K_{1} x_{n-1}^{2} \\
& -K_{2} x_{n-1}\left(1-\theta_{n-1}\right)+K_{2} x_{n-1}\left(\theta_{n}-\theta_{n-1}\right) .
\end{aligned}
$$

Hence it follows that for $i=2, \ldots, n$,

$$
\begin{aligned}
y_{i}= & y_{i-1}+K_{1} x_{i}^{2}+\left(1-\theta_{i}\right) K_{2} x_{i}-K_{1} x_{i-1}^{2} \\
& -\left(1-\theta_{i-1}\right) K_{2} x_{i-1}+\left(\theta_{i}-\theta_{i-1}\right) K_{2} x_{i-1} .
\end{aligned}
$$

After substituting the incentive function [equation (25)] into equation (21) the optimal $x$ is given by:

$$
x_{i}=\frac{p_{i} \lambda_{i}-K_{2}\left(\left(1-\theta_{i}\right) p_{i}+\left(\theta_{i+1}-\theta_{i}\right) \sum_{k=i+1}^{n} p_{k}\right)}{2 p_{i} K_{1}}
$$

for $i=1,2, \ldots, n$. As pointed out in the "Mechanism Design" chapter, one needs to check for the monotonicity of $x$. Once $x_{i-1} \leq x_{i}$ the monotonicity condition is satisfied. This analysis was done in [6] for the continuous case, and the constraints for the discrete case are developed in the appendix of this thesis.

The contracts are governed by customer type and customer location. Customer cost function calibration helps identify the types. The locational value of power can be calculated using sensitivity methods [7], or optimal power flow routines [3], [8].

\section{NUMERICAL EXAMPLES}

Initially we compare the proposed contracts to the existing contracts, then a comparison is made between the proposed contracts designed with different kinds of cost functions.

\section{A. Example 1: Comparison of Proposed Contracts with the Existing Contracts}

The first example consists of 10 customers selected from utility-provided data. These customers are currently on a demand management program that pays them a fixed rate of $\$ 3.25$ per available $\mathrm{kWh}$ for curtailment. After applying the proposed cost function calibration and designing new contracts using mechanism design, there is an increase in both total amount of available relief and total profit by the utility (see Table III). The utility benefit is maximized after the contracts are designed using mechanism design, and in this Similar derivations can be 
TABLE III

COMParison of CONTRACTS WITH 10 Customers, VALUE OF POWER EQual at EACH Customer LoCATION (QUadRatic OUTAGE Cost FUNCTION ASSUMPTION)

\begin{tabular}{ccc}
\hline & Total & Total Utility \\
Relief & Benefit \\
\hline Proposed Contracts & $2919.70 \mathrm{~kW}$ & $\$ 2011.84 / \mathrm{hr}$ \\
Existing Contracts & $2760.00 \mathrm{~kW}$ & $\$ 1518.00 / \mathrm{hr}$ \\
\hline \multicolumn{3}{c}{ Increase in Relief $=159.70 \mathrm{~kW}$} \\
Increase in Benefit $=\$ 493.84 / \mathrm{hr}$ \\
\hline
\end{tabular}

TABLE IV

COMPARISON OF CONTRACTS WITH 15 CUSTOMERS, VALUE OF POWER Equal at EACH Customer LoCATION (QUADRATIC OUTAGE COST FUNCTION ASSUMPTION)

\begin{tabular}{ccc}
\hline & Total & Total Utility \\
Relief & Benefit \\
\hline Proposed Contracts & $11069.51 \mathrm{~kW}$ & $\$ 10930.95 / \mathrm{hr}$ \\
Existing Contracts & $12000.00 \mathrm{~kW}$ & $\$ 9225.00 / \mathrm{hr}$ \\
\hline \multicolumn{3}{c}{ Reduction in Relief $=930.49 \mathrm{~kW}$} \\
Increase in Benefit $=\$ 1705.95 / \mathrm{hr}$ \\
\hline
\end{tabular}

TABLE V

COMPARISON OF CONTRACTS WITH 15 CUSTOMERS, VALUE OF POWER NOT EQual at EACH Customer Location (QuAdratic OUTAGE Cost FUNCTION ASSUMPTION)

\begin{tabular}{ccc}
\hline & $\begin{array}{c}\text { Total } \\
\text { Relief }\end{array}$ & $\begin{array}{c}\text { Total Utility } \\
\text { Benefit }\end{array}$ \\
\hline Proposed Contracts & $12092.63 \mathrm{~kW}$ & $\$ 14155.33 / \mathrm{hr}$ \\
Existing Contracts & $12000.00 \mathrm{~kW}$ & $\$ 11825.00 / \mathrm{hr}$ \\
\hline \multicolumn{3}{c}{ Increase in Relief $=92.63 \mathrm{~kW}$} \\
Increase in Benefit $=\$ 2330.33 / \mathrm{hr}$ \\
\hline
\end{tabular}

used to come up with the contracts using exponential customer cost functions.example there is an increase in available relief. Table IV shows another case where a sample of 15 customers is taken from the utility-provided data. This time total relief is less than the total under the existing contracts even though the total benefit is increased. Existing contracts are paying these customers $\$ 3.25$ per $\mathrm{kWh}$ if the customer is signed up for relief under $500 \mathrm{~kW}$, and $\$ 3.00$ per $\mathrm{kWh}$ for relief above $500 \mathrm{~kW}$.

Mechanism design generally deals with tradeoffs and the design of contracts of products that have a unique value to a principal. Such is not the case for electric power. The value of a contract depends on the location of the customer. In order to do this, we have extended mechanism design to permit the incorporation of locational attributes. This is done by a parameter $\lambda$ as shown in previous sections. In order to demonstrate how locational value can help increase both the total available relief and the total benefit for the utility, the locational value for 5 of the customers, who are more willing to curtail power than the others, are increased. Since the formulation takes advantage of locational attributes of the customers the proposed contracts yield both increased total available relief and total utility benefit (see Table V).

Total available relief is very sensitive to changes in locational value. The same is true for total utility benefit, but when mechanism design is used to design the contracts, the utility benefit
TABLE VI

COMPARISON OF CONTRACTS DESIGNED WITH DifFERENT Cost FUNCTION ASSUMPTIONS

\begin{tabular}{ccc}
\hline & $\begin{array}{c}\text { Total } \\
\text { Relief }\end{array}$ & $\begin{array}{c}\text { Total Utility } \\
\text { Benefit }\end{array}$ \\
\hline Prop. Contracts (quad) & $2864.69 \mathrm{~kW}$ & $\$ 1903.72 / \mathrm{hr}$ \\
Prop. Contracts (expo) & $2546.59 \mathrm{~kW}$ & $\$ 2435.85 / \mathrm{hr}$ \\
Existing Contracts & $2760.00 \mathrm{~kW}$ & $\$ 1518.00 / \mathrm{hr}$ \\
\hline Increase in Relief (quad) $=104.69 \mathrm{~kW}$ \\
Increase in Relief (expo) $=-213.41 \mathrm{~kW}$ \\
Increase in Benefit (quad) $=\$ 385.72 / \mathrm{hr}$ \\
Increase in Benefit (expo) $=\$ 917.85 / \mathrm{hr}$ \\
\hline
\end{tabular}

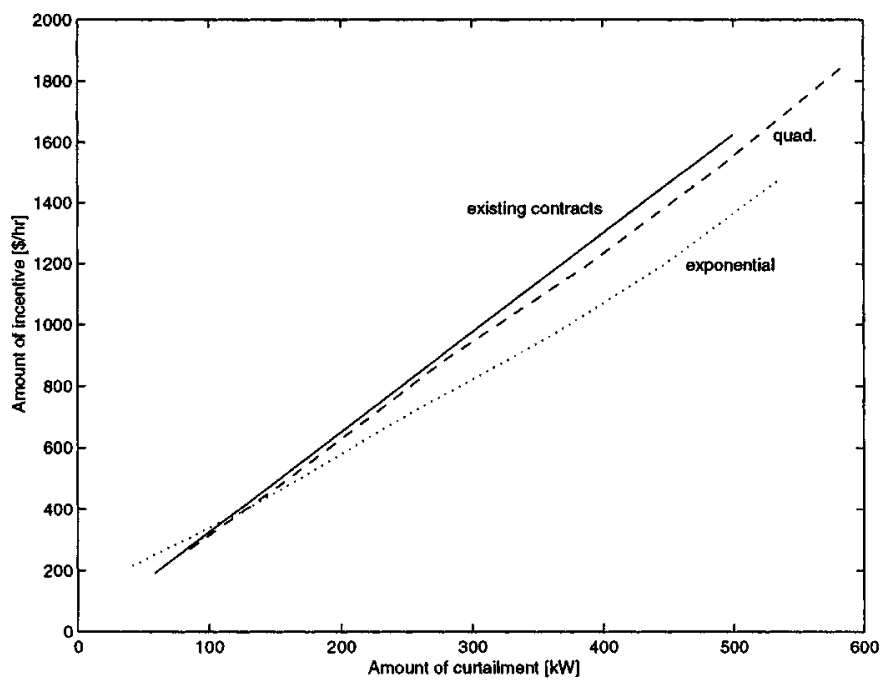

Fig. 4. Existing contracts (dashed line) vs. proposed contracts (solid line).

always increases ${ }^{6}$ in comparison to existing contracts. There is no such guarantee for the total available relief. However, when location is incorporated into the contract design process, it provides a tool which lets the utility get demand management contracts at critical locations. More valuable contracts are offered at high impact locations in the grid. System problems can now be solved more efficiently by having demand management contracts at the right locations.

\section{EXAMPLE 2: QUADRATIC VS. EXPONENTIAL COST FUNCTION CONTRACTS}

Another study was performed where the contracts designed with a quadratic cost function assumption was compared to the contracts designed with an exponential cost function assumption. This example was worked out in order to test the robustness of the formulation and to see its sensitivity to the shape of the cost function. The contracts designed using an exponential cost function for the customer outage cost function show the most monetary benefit for the utility (if the exponential assumption is correct). Furthermore this is achieved by using the least amount of available relief (see Table VI). Hence, if the behavior of customers is indeed according to an exponential outage cost function, the benefit to a utility will be greater. This example was done to show the ability of the mechanism to work with different

${ }^{6}$ Mechanism design is formulated to maximize utility benefit. 
cost functions. However, our previous analysis and the current literature on the subject both support the idea of a quadratic cost function. The range of the contracts in this example is depicted in Fig. 4.

\section{CONCLUSION}

Available data on current demand management contracts can be used to calibrate the customer cost function and help design better demand management contracts. The key to having efficient demand management contracts is having a good estimate of the customer outage cost function. If the estimated cost function is correct utilities can optimize the amount of compensation they offer in return for curtailment. The developed formulation maximizes total utility benefit and makes sure the available relief is coming from the right locations.

\section{ACKNOWLEDGMENT}

The authors would like to thank MG\&E and WEPCO for providing the data.

\section{REFERENCES}

[1] M. Beenstock, "Generators and the cost of electricity outages," Energy Economics, 1991.

[2] D. W. Caves, J. A. Herriges, and R. J. Windle, "The cost of electric power interruptions in the industrial sector," Land Economics, vol. 68, no. 1, pp. 49-61, 1992.

[3] H. W. Dommel and W. F. Tinney, "Optimal power flow solutions," IEEE Trans. on Power Apparatus and Systems, vol. PAS-87, no. 10, pp. 1866-1876, Oct. 1968
[4] M. Fahrioglu and F. L. Alvarado, "The design of optimal demand management programs," in Proceedings of Bulk Power System Dynamics and Control IV-Restructuring, Santorini, Greece, Aug. 1998.

[5] — - "Designing cost effective demand management contracts using game theory," in Proceedings of the IEEE PES Winter Meeting, New York City, Jan. 1999.

[6] D. Fudenberg and J. Tirole, Game Theory: The MIT Press, 1991.

[7] S. Greene, I. Dobson, and F. L. Alvarado, "Sensitivity of the loading margin to voltage collapse with respect to arbitrary parameters," IEEE Trans. on Power Systems, vol. 12, no. 1, pp. 262-272, Feb. 1997.

[8] M. Huneault and F. D. Galiana, "A survey of the optimal power flow literature," IEEE Trans. on Power Systems, vol. 6, no. 2, pp. 762-770, May 1991.

[9] "Electric power research institute. Designing an integrated menu of electric service options. Modeling customer demand for priority service using C-VALU-the Niagara Mohawk application,”, Technical Report TR-100523, EPRI, Oct. 1992.

Murat Fahriog̃lu (S'92) received the B.S. (Hon) degree in electrical engineering from Michigan State University, the M.S. and the Ph.D. degrees from the University of Wisconsin-Madison. His main interests are in game theory applications in power systems and more specifically in the design of demand management contracts between electric utilities and their customers to avoid forced outages.

Fernando L. Alvarado (F'93) received the B.S. degree from the National University of Engineering in Lima, Peru, the M.S. degree from Clarkson University, and the Ph.D. degree from the University of Michigan. He is currently a Professor at the University of Wisconsin-Madison in the Department of Electrical and Computer Engineering. His main interests are power systems congestion and pricing, system security, computer applications to power systems and large scale computations. 